\title{
DENTRE PLANTAS E MULHERES - A PORTA DE ENTRADA DO UNIVERSO MÍSTICO E POÉTICO QUE ENVOLVE MULHERES EM SALVATERRA
}

\author{
AMONG PLANTS AND WOMEN - THE GATEWAY TO THE MYSTICAL AND POETIC \\ UNIVERSE WHICH INVOLVES WOMEN IN SALVATERRA
}

\author{
Lanna Beatriz Lima Peixoto ${ }^{i}$ \\ Flávio Leonel Abreu da Silveira ${ }^{2}$
}

\begin{abstract}
Resumo: Neste trabalho apresentamos reflexões preliminares de um estudo sobre o universo mítico que envolve as mulheres e o feminino na região do Marajó. Apresentamos dados das primeiras duas viagens a campo, onde destacam-se duas mulheres em específico: dona Marta, no distrito de Joanes, e dona Joana, em uma comunidade quilombola, ambas localizadas no município de Salvaterra. Aqui, expomos alguns apontamentos suscitados pelo encontro com essas duas mulheres, de forma a pensarmos as suas experiências a partir do diálogo com uma bibliografia específica. A princípio a existência de um mote em comum auxiliou-nos a adentrarmos no universo de seus cotidianos e, mais diretamente de seus quintais, desde onde os saberes relacionados às plantas medicinais emergiram como a ponta de um novelo, que compreende memórias e os saberes em torno de práticas de cura, do xamanismo e do misticismo local, envolvendo, principalmente, a figura feminina que pretendemos abordar ao longo da discussão presente neste artigo.
\end{abstract}

Palavras-chave: Plantas, mulheres, quintal, perspectiva.

\begin{abstract}
In this present study we show preliminary reflections about the mythical universe involving women and female space in the Marajó region. We present data from the first two trips to the countryside, where we highlight two women in particular: Mrs.Marta in Joanes district, and Mrs. Joana, in a "quilombo", both located in the municipality of Salvaterra. Here, we expose some notes raised by the encounter with these two women, to think about their experiences from the dialogue with a specific bibliography. At first the existence of a common theme helped us we enter the universe of their daily lives and more directly from their yards, from where the knowledge related to medicinal plants have emerged as the tip of a ball, comprising memories and knowledge in around healing practices of shamanism and local mysticism, involving mainly the female figure we intend to address this during the discussion in this article.
\end{abstract}

Keywords: Plants, women, yard, perspective.

\section{Refletindo sobre o tema}

Percorrer o território do município de Salvaterra por seus cursos d'água, seguindo os rastro deixados pelas mulheres que compuseram a pesquisa de dissertação da primeira autora sobre a relação da cidade com as águas é um desafio. Durante essa pesquisa foi possível escutar diversas vezes que "o encantado não acaba, ele se afasta". A partir de tal perspectiva almejamos o encontro com mulheres que guardam memórias que nos permitam acessar essas paisagens fantásticas, onde figuram imagens de encantarias e, assim, compreendermos aspectos do universo místico e mítico que as envolve. Duas visitas foram feitas, uma ao distrito de Joanes, no mês de junho de 2015, e outra à uma das comunidades quilombolas da região, em agosto de 2015, quando conhecemos respectivamente dona Marta e dona Joana.

\subsection{Da cidade ao quintal}


"Salvaterra é um segredo", disse Carlos Drummond de Andrade no conto "A moça contou". A primeira estadia na cidade, em 2009, foi suficiente para percebermos a profundidade dessa afirmação que ensinou, e nos ensina até hoje, a respeitar os mistérios do mundo e saboreá-los. O município de Salvaterra, Estado do Pará, está localizado no Arquipélago do Marajó, região dos Campos, que compreende também os municípios de Cachoeira do Arari, Chaves, Muaná, Ponta de Pedras, Santa Cruz do Arari e Soure.

É banhada pela Baía do Marajó e pelo Rio Paracauari, sendo entrecortada por rios, lagos, furos e igarapés. Salvaterra foi elevada à condição de município somente em 1961, pois antes disso era conhecida como Vila de Salvaterra, distrito do município de Soure. Foi colonizada por volta do século XVII por frades jesuítas. Antes da chegada de europeus especificamente, a área que compõe o município era usada como um local de reunião dos grupos indígenas que habitavam a área, a fim de realizarem trocas de vários gêneros, assim como, para fins de defesa de seu território contra invasões externas.

Com a chegada dos portugueses àquele território, nominaram a área de Salvaterra, tal qual uma cidade localizada em seu país de origem, Salvaterra dos Magos. Sobre isso, foi Dona Sebastiana, antiga moradora do local, que nos deu a informação mais interessante, pois segundo ela o nome havia sido escolhido por conta de uma similaridade específica entre as duas cidades: a homônima brasileira tinha em comum com a portuguesa a vocação à magia e ao misticismo. Os portugueses encontraram aqui tantos pajés quantos magos haviam na Salvaterra portuguesa. Os antigos salvaterrenses afirmam que ali já existiram grandes "cirurgiões", "curadores", "curandeiros", entre outras definições usadas para aqueles que seriam os responsáveis pela saúde física e espiritual dos filhos da terra, bem como de muitos outros que vinham de longe procurá-los.

Hoje, mesmo com a diminuição da prática da pajelança - como afirmam moradores do local -, persistem saberes repassados de geração a geração em torno dos usos destinados às plantas e às receitas para uma infinidade de mazelas, desde àquelas referentes ao corpo e à alma. Esses conhecimentos foram a nossa porta de entrada ao universo cosmológico de mulheres em Salvaterra. Eles se concentraram principalmente entre elas, talvez, por serem tradicionalmente responsáveis pelos cuidados com os filhos e a família de um modo geral. O que é interessante observar, tendo em vista que as mulheres que se dedicavam às práticas de cura, magia ou xamanismo, sempre foram associadas ao lado negativo dessas práticas, não raro sendo relacionadas às "figuras de personagens malfazejas" (MOTTA-MAUÉS, 2008, p.333), como as feiticeiras e as matintas ${ }^{3}$.

A questão da mulher em relação com a magia e ao misticismo já figurou e figura ainda hoje entre as atenções de muitos antropólogos. Marcel Mauss, no texto "Esboço de uma teoria geral da magia" (MAUSS, 2003) aponta uma predisposição histórica de atribuição de características mágicas às mulheres. Para ele, seria menos os caracteres físicos e mais "sentimentos sociais" que suscitam tais 
atributos, em decorrência das fases e ciclos por que passam. A apreensão desses períodos conferem uma posição social ambígua e movente, liminar. Períodos como puberdade e menopausa, cíclicas menstruais, são considerados críticos e, por isso mesmo, mais inclinados à magia. Ao contrário do homem, que teria um estatuto mais fixo, a mulher é tida como um "sujeito transitante" (TURNER, 1974, p. 118 apud MOTTA-MAUÉS, 2008, p.330), permanecendo envolta em um mistério de constituição, um enigma. Para Marcel Mauss:

[...] mesmo fora das épocas críticas, que ocupam tão grande parte de sua existência, as mulheres são o objeto seja de superstições, seja de prescrições jurídicas e religiosas, que marcam claramente que elas formam uma classe no interior da sociedade. Acredita-se serem ainda mais diferentes dos homens do que o são; acredita-se serem o foco de ações misteriosas e, por isso mesmo, aparentadas aos poderes mágicos.

(MAUSS,2003, p. 65)

A mulher transitaria entre os domínios, abrigando no corpo a liminaridade entre cultura e natureza, imiscuindo em si as polaridades. Tal oposição, para Angélica Motta-Maués acarreta uma inversão no que se refere ao contexto social. Aos homens, por serem dotados de estabilidade "é permitido circular e atuar, livre e efetivamente, em qualquer domínio, de qualquer área do sistema social, ao passo que à mulher são impostos limites rígidos, restringindo-se drasticamente as oportunidades para o seu desempenho social" (MOTTA-MAUÉS, 2008, p.330). Emerge daí a distribuição dos papeis que oscilam entre público e privado, a casa e a rua, com a consequente demarcação de domínios para o masculino e para o feminino.

À interioridade de si e da casa foram os espaço reservados socialmente às mulheres e, portanto, a uma esfera da intimidade. Nesse artigo, adentramos e caminhamos pelo interior da morada, mais especificamente pelo quintal: a área externa atribuída socialmente à um ser perigoso e afeito às desordens como seria a mulher, cujos limites horizontais concretos delimitam suas escolhas sociais, mas a falta deles verticalizaria seus atributos, tanto em relação à terra, como ao céu; o cultivo de plantas ornamentais, medicinais e, por isso, numa esfera de interação entre não-humanos e humanos; às preocupações com seus filhos, às sutis relações com o sagrado e o si-mesmo.

Este seria o universo sensível onde figuram Joana e Marta, ambas têm mãos boas, porque na terra onde tocam tudo dá. Ser mulher tem dessas vantagens, guardam no corpo a conexão com as coisas da natureza, facilitando a comunicação com as coisas de ciclos, que movem determinadas energias. Percebemos no desenho de suas rugas, como se neles estivessem impressos os caminhos d'água que umedecem a terra da região que elas tão bem conhecem: esses caminhos estão também nas plantas, como se fossem água, unindo mulheres e plantas como continuação umas das outras.

Quando contam as velhas senhoras brotam também - nelas emergem, florescem narrativas fornecendo aos de bons ouvidos palavras de um mundo de encantarias e sentidos imersos em um 
cotidiano movido por dias quentes e noites visagentas. É sobre esse processo que versa esse artigo. Sobre a vida em sua mobilidade que extrapola os corpos e dilui as formas, como uma alquimia de todas as coisas. A mulher cultiva a terra, a planta cultiva o humano, cura-o. Há uma domesticação e um acolhimento recíproco. Existem chás para tudo, desde as doenças de estômagos às doenças do espírito: socialidades que envolvem cuidados comuns, agências sutis que significam afinidades. A alquimia se dá não só na preparação dos chás, mas também na atmosfera que envolve mulheres, as águas e as plantas, entrelaçando a matéria das coisas ao sobrenatural e ao racional por intermédio do sensível e, por isso mesmo, do imaginário.

\section{Dona Marta}

Fomos apresentados a Dona Marta por uma querida amiga, sua neta. Dona Marta tem 64 anos e mora em Joanes há 15, onde vive sozinha desde que o marido faleceu. Quando a vimos pela primeira vez era exatamente como esperávamos, muito parecida com a neta, Lilianne. Cabelos negros e espessos, pele morena, baixa estatura, sorriso aberto, covinhas que lhe dão ar de menina, fala rápida, nasal. Ela nos acolheu e saímos de lá com a sensação de termos uma avó marajoara. Assim que chegamos ficamos sabendo que era evangélica, missionária da igreja Assembleia de Deus. Fato que a princípio reduziu nossas expectativas sobre conversas em torno das encantarias que permeiam o imaginário na região já que, sabidamente, trata-se de um tema tabu.

Porém, na manhã seguinte durante o café, enquanto comíamos ela começou a contar sobre sua relação com a neta que ajudou a criar e, posteriormente, sobre uma séria doença que Lilianne teve quando criança. O desenrolar dessa conversa surpreendeu-nos, pois as lembranças da doença da menina suscitaram narrativas cheias de emoções e saberes sobre cura e o poder das plantas num contexto xamanístico que nos pareceu fazer aquela manhã durar anos.

Dona Marta passou a mostrar suas plantas e, de sua narrativa fluíram enxurradas de receitas para todos os males, que vieram à tona mediante os seus devaneios. Logo receitou um chá de capim santo para a cólica que Lanna sentia no momento. Ao caminharmos pelo seu quintal percebemos o quão poderoso é aquele lugar, sua potência imagética, as narrativas que guardam cada uma daquelas plantas, raízes, caules e folhas distribuídas na localidade do espaço doméstico. Dona Marta, ali, ora sentada em algum toco de árvore, ora caminhando por entre as espécies, cantando folhas e frutos do chão, e levandoos a boca, oferecendo-os a nós, parecia que também crescera, florescera, habita aquele espaço como as plantas com quem tem tanta intimidade. As receitas de dona Marta não eram simples remédios às doenças do corpo, pois guardam um conhecimento atribuído e uma memória de afetos que envolvem tanto a relação entre os seres humanos ligados ao tratamento e na cura, como os não humanos, às plantas e também a certos animais. 
Depois dos relatos sobre as plantas e a caminhada pelo quintal vieram seus encontros com a Matinta e os conselhos de como proceder nos locais encantados, tantos são eles naquela região. Foi possível perceber o quanto o conhecimento sobre o uso de plantas medicinais está atrelado à um universo cosmológico mítico e mágico. Depois, Lilianne contou-nos que antes de se tornar protestante, a avó era católica, mas frequentava constantemente terreiros e curandeiros. Nestes casos ia em busca da cura para doenças, como no caso da moléstia que a atingira quando criança, ou a procura de conselhos, como quando se separou do ex-marido, avô de Lilianne, que a deixou para ficar com uma prostituta do local em que moravam. Hoje, esse hábito ficou para trás, mas a crença nos elementos que figuram esse universo claramente ainda está viva em dona Marta.

Eduardo Galvão, em 1953, afirmava que religião predominante na Amazônia era o catolicismo, que se manifestava, sobretudo, "no culto aos santos, ou mais propriamente as suas imagens locais, a que se empresta caráter de divindade com poderes de ação imediata e não apenas representações de intermediários entre uma força superior e o homem" (GALVÃO, 1953, p.53). O que já fornece, desde uma perspectiva amazônida, outro tom ao catolicismo comparado ao oficial. O culto às imagens católicas acabou conversando muito bem com uma série de seres encantados e outras entidades, como os orixás trazidos pelas populações de descendência africana. Galvão observou que assim foi se compondo o todo religioso, dessas infindas e complexas imagens que se entrecruzaram no contexto amazônico ao longo do tempo.

Para o autor este todo contribui à uma "ciência do caboclo" (GALVÃO, 1953, p. 10), que seria utilizada para "dominar o ambiente que o cerca" (ibid). Para Galvão as mais variadas técnicas utilizadas nos diferentes trabalhos que empreende o "caboclo" estariam baseadas na experiência tradicional intimamente relacionado ao conhecimento empírico, mesclados à uma concepção mágica do universo que estabeleceria formas de proceder no ambiente, entre comportamentos e normas coletivos. LéviStrauss avança nessa discussão quando afirma que essa "ciência", não estaria orientada e baseada somente nos trabalhos de subsistência, mas se constituem também de

[...] pensamentos desinteressados; ou seja, são movidos por uma necessidade ou um desejo de compreender o mundo que os envolve, a sua natureza e a sociedade em que vivem. Por outro lado, para atingirem este objectivo, agem por meios intelectuais, exactamente como faz um filósofo ou até, em certa medida, como pode fazer e fará um cientista.

(STRAUSS, 1987, p. 26)

[...] que toda sociedade tende a perseverar no seu próprio ser, e que a cultura é a forma reflexiva deste ser; pensamos que é necessário uma pressão violenta, maciça, para que ela se deforme e transforme. Mas, sobretudo, cremos que o ser de uma sociedade e seu perseverar: a memória e a tradição são o mármore identitário de que é feita a cultura. Estimamos, por fim, que, uma vez convertidas em outras que si mesmas, as sociedades que perderam sua tradição não têm volta. Não há retroceder, a forma anterior foi ferida 
de morte; o máximo que se pode esperar e a emergência de um simulacro inautêntico de memória, onde a 'etnicidade' e a má consciência partilham o espaço da cultura extinta (ibid).

Como observamos nas várias narrativas contadas por dona Marta, não se trata somente de uma questão identitária, de aculturação ou simples assimilação. Não negamos que hajam, sim, imposições, subjulgações e dominações entre culturas contrastantes. Especificamente no caso do pentecostalismo é impossível negar a expansão de uma moralidade que exclui, e também corrói práticas tradicionais de cura, magia e xamanismo; e mesmo, que os reais conflitos identitários e de pertencimento que envolvem perseguições e violências, físicas inclusive, estão presentes no contexto amazônico. Mas também há nesse processo algo "da ordem de um devir, do que se torna, do que se transforma em outra coisa diferente do que se era e que, de algum modo, conserva uma memória do que se foi” (MELLO, 2003, p. 95 apud GOLDMAN, 2014, p.214). E esses meandros devem também ser percebidos, compreendidos.

\section{Dona Joana}

Fomos à Mangueiras a primeira vez durante o trabalho de campo da pesquisa de mestrado, em janeiro de 2014. Dona Joana foi a primeira mulher que conhecemos no local. Seu filho, Marquinho, era então o presidente da associação dos quilombolas da comunidade, por isso sua casa era comumente o ponto de chegada dos visitantes na comunidade. Antes de chegarmos fomos aconselhados por Lira morador de Salvaterra que nos guiou nessa visita - a não tomar ou comer nada que ela nos oferecesse até o final. Caso contrário ela poderia descobrir nossos segredos. Segundo ele, Mangueiras teria muitas feiticeiras, precisaríamos ter cuidado até com os olhares. Ele não falou muito mais do que isso, mesmo com minhas perguntas sobre a advertência, respeitei seu silêncio. A visita durou apenas dois dias, o que impossibilitou que conversássemos mais com a senhora ou soubéssemos mais sobre ela.

A segunda visita à comunidade foi em julho de 2015, agora em virtude da pesquisa de doutorado da primeira autora. Dona Joana se lembrava muito bem de nós e das pessoas que estiveram lá conosco na primeira vez que a visitamos. Dessa vez conversamos bastante, não só com ela, a aproximação se deu também com outros moradores e, principalmente com as crianças do local. Esse maior contato esclareceu alguns pontos, mas sentimos que em verdade nos fizeram mergulhar mais fundo no mistério que ronda essa senhora e a comunidade como um todo.

A comunidade é uma das 16 comunidades de remanescentes de quilombo de Salvaterra. Segundo seus moradores, dentre todas elas, composta por 4 povoados e com mais de 200 anos, é a real comunidade de origem quilombola no município. Ali encontramos ancestrais diretos dos antigos escravos da região, de negros e índios. Chegando lá o que logo salta à vista é a quantidade de meninas que andam por suas 
ruas a todo momento, muito superior a de meninos. Parece ser muito maior o número de mulheres em comparação com o número de homens na comunidade. Muitos podem ser os motivos, mas no momento não podemos fazer mais do que essa constatação. A história da comunidade é marcada pelas mulheres fortes, de muitos filhos e grandes mistérios.

Dona Joana tem 67 anos e sempre morou na comunidade. Trabalhava em fazendas próximas quando jovem, hoje já quase não sai de casa, onde se ocupa com as mais diversas tarefas, entre elas o cuidar das plantas no quintal. Dona Joana guarda no olhar mistérios que cremos nunca acessar, ao mesmo tempo uma bondade, como as mãos negras que entregavam as folhas das plantas do quintal, que retirava com ternura e respeito. Apesar de ser presença constante nas sessões de batuque, ou macumba, como ela mesmo chama, a senhora afirma ser católica. Inclusive, relatou algumas brigas com familiares que se converteram ao protestantismo. Uma irmã protestante está doente, dona Joana conclui que por conta da religião não fica curada, se fosse católica ao menos poderia recorrer a um pajé que lhe auxiliasse no trato da doença, o que o protestantismo, segundo ela, não permite.

No início disse-nos que não sabia se podia ajudar porque não tinha mais tantas plantas, só as que o gado, que vive solto pela comunidade, esqueceu de comer. Ao longo das conversas ficamos imaginando como seria seu quintal se ela tivesse muitas. Começou pelas plantas do jardim, as que ficam em frente à sua casa, ao lado do portão, pois existe uma quantidade significativa de espécies que ela maneja com cuidado. Algumas são as que espantam olho-gordo e atraem as coisas boas, as que ficam no quintal são as frutíferas e de cura. São inúmeras, passamos horas de uma a outra, ela ria com as perguntas e a cada hora se lembrava de uma receita diferente.

Se não soubéssemos que estávamos ali no centro da comunidade, poderíamos pensar que estávamos caminhando por uma mata densa e fechada, por caminhos e trilhas que a senhora conhecia como as linhas da própria mão. O quintal de dona Joana é como uma outra dimensão dentro da comunidade. Nele há marcas de uma paisagem (BERQUE, 1998) que indicam as experiências e as visões de mundo de uma persona, um universo íntimo e particular que só ela tem acesso em sua completude. Um quintal-floresta, quintal-microcosmos, quintal-mulher, mulher-floresta, a morada de dona Joana.

Perguntamos como ela conseguia tantas plantas, ao que respondeu, simplesmente, por "trocas". Constatamos uma rede solidária de "trocas" de plantas entre mulheres de dentro da comunidade, o que forma uma circularidade dadivosa e recíproca de entes não-humanos vivos com poderes curativos e mágicos. Cada planta exige um trato especial, uma forma apropriada de plantar e de cuidar, o que desdobra-se nos cuidados do Outro-doente, ou de si. A cura, como um processo simbólico-prático resulta de interações interespécies sutis entre plantas-herbolária-paciente como expressões de uma totalidade cósmica cabocla. 
Desde a pronúncia do nome já sentimo-nos instigados, movidos pela curiosidade sobre a história da planta: como a sombra-do-mundo, o boldo sacaca, ou o peão-de-angola. Com elas se fazem chás, pomadas, óleos e banhos para todos os fins, e como gostam de banhos de ervas os moradores daquele lugar, estão sempre envolvidos em seus preparos. Principalmente as plantas de cheiro forte - como a canela, a catinga de mulata e o peão de angola - as quais são utilizadas em preparos para banhos voltados a diversos fins, tais como atrair dinheiro, pescado, amor, além da cura para as mais variadas doenças. Sempre que as pessoas passam pela frente da casa de dona Joana tiram uma folhinha do pé de peão-roxo para colocar atrás da orelha, ou de baixo do chapéu para atrair os bons fluidos.

Perguntamos a dona Joana como ficara sabendo das receitas, quando fizemos essa pergunta ela manuseava uma folha de pariri. Ela informou que o remédio oriundo daquela planta, em específico, havia chegado a ela através de um sonho: "Sonhei que eu tinha que beber o chá dessa planta pra curar uma dor no fígado. Fiz e fiquei boa!” As receitas geralmente são repassadas por pajés a cada doente, a cada doença que acomete a pessoa. Outra forma de transmissão ocorre entre a rede de troca já mencionada. Sempre que há alguém doente na família não tardam a surgir as receitas e plantas a fim de curar os males da pessoa. Percebemos que a doença naquela comunidade não é tida como uma questão individual, mas um problema que mobiliza todo o grupo familiar, onde muitas vezes pode se encontrar também suas causas. Portanto, somente com o envolvimento de todos os membros é possível também alcançar a cura porque ela é eminentemente uma questão social.

Algumas meninas da comunidade nos acompanharam durante toda nossa estadia, quando dissemos a elas que iríamos à casa da senhora percebemos certo mal-estar, algumas risadinhas, inclusive uma das meninas abandonou o grupo por isso. Durante o tempo que estivemos lá Dona Joana brigou com as meninas que pegavam laranjas do quintal, porque são vendidas, não dadas. As meninas saíram de sua casa e nos esperaram em frente. Depois que saímos de lá elas começaram a resmungar sobre a senhora, questionadas sobre qual o motivo do desgosto falaram que tinham medo dela, pelo fato de ser malvada e virar bicho, que tinham testemunhas que chegaram a ver a senhora "engerando em porco" no quintal. Mas assim como Lira fizera noutro momento, desviaram o assunto e não quiseram dar mais informações sobre a questão.

Engerar é uma categoria amazônica que designa um processo mágico de metamorfose. Como constatou João Valentin Wawzyniak, existem seres que possuem um poder de transformação, em certas circunstâncias esses seres "transfiguram suas aparências e comportamentos, regulam e afetam o corpo e a vida cotidiana individual e coletiva" (WAWZYNIAK, 2012, p.19). Segundo este autor há princípios que norteiam essa relação, que se baseiam principalmente em: 
[...] um sistema cultural que postula a não existência de dicotomia ou antagonismo entre as dimensões natural, cultural e sobrenatural, mas, em seu lugar, postula um universo transformacional e povoado por uma pluralidade de agentes, humanos e não humanos (WAWZYNIAK, 2012, p.19) ().

Há um universo transformacional, uma metamorfose de aparências que amplia a noção de humanidade. Um "bicho", como chamam em Mangueiras são os seres dotados dessa capacidade de transformação, metamórfica. Geralmente são humanos que assumem a forma animal, ou seja transfiguram-se na aparência e no comportamento de certos animais, como o porco, o cavalo, entre outros, ou vice-versa. Viveiros de Castro fala sobre o regime de metamorfose:

\begin{abstract}
A questão de saber se o jaguar mítico, por exemplo, é um bloco de afetos humanos em figura de jaguar ou um bloco de afetos felinos em figura de humano é rigorosamente indecidível, pois a metamorfose mítica é um acontecimento ou um devir (uma superposição intensiva de estados heterogêneos), não um processo de mudança (uma transposição extensiva de estados homogêneos). Mito não é história justamente porque metamorfose não é processo, "ainda" não é processo e "jamais foi" processo; a metamorfose é anterior e exterior ao processo do processo - ela é um devir.
\end{abstract}

(CASTRO, 2006, p. 323)

Nesse sentido, o humano não deixa de ser humano porque virou porco, e muito menos o porco é menos porco por ter sido humano, as condições são reafirmadas em superposição. Para Viveiros de Castro, boa parte da mitologia ameríndia está fundamentada sob a "condição geral instável na qual aspectos humanos e não-humanos se acham inextricavelmente emaranhados", portanto, todos os seus personagens partilham um entrelaçamento ontológico, o que o autor chama de "ambiguidade transespecifica" (CASTRO, 2006, p. 322). Há, então "uma unidade do espirito e uma diversidade dos corpos" (CASTRO, 2002, p. 349). Quando questionamos uma das crianças sobre como sabia sobre a transformação de dona Marta, ela disse que havia testemunhas que viram um porco correr para os braços de um dos filhos da senhora, no meio da noite depois de uma festa. Portanto, o porco saberia exatamente que era o filho que abraçava.

É nesse sentido que a teoria do perspectivismo trabalhada por Viveiros de Castro e, posteriormente, por João Valentin Wawzyniak (WAWZYNIAK, p. 2003) e Raymundo Heraldo Maués (2012) - que a trabalharam no sentido de sua expansão para pensar, além do indígena o universo cosmológico de populações não indígenas na Amazônia - cabe, também, a este estudo. Para Maués, o "perspectivismo indígena não é só indígena, mas é partilhado em grande medida pelas populações rurais não indígenas de muitas áreas da Amazônia” (MAUÉS, 2012, p. 55).

O perspectivismo está relacionado à forma como os seres veem o mundo. De acordo com Viveiros de Castro o perspectivismo consiste em uma "concepção segundo a qual o mundo é habitado 
por diferentes espécies de sujeito ou pessoas, humanas ou não-humanas, que o apreendem segundo pontos de vista distintos" (CASTRO, 2002, p. 347). Segundo esta visão a condição humana é expandida a qualquer espécie que seja pensada como sujeito e dotada de intencionalidade. Porém, faz-se necessário pensar o perspectivismo de Viveiros de Castro também por um viés crítico, principalmente ao que se refere a defesa de um tipo único de perspectivismo. O perspectivismo deve ser encarado muito mais como perspectivismos (SANTOS-GRANERO, 2006, p. 121), tendo em vista a pluralidade de formas de pensamento indígena e a sua influência muito variada sobre as populações não indígenas na Amazônia, diante de sua pluralidade étnica e biodiversa.

Sendo assim, percebendo os mistérios que rondavam dona Joana, tentamos uma incursão mais profunda sobre seus conhecimentos acerca dos encantados e dos bichos, se acreditava em visagens e se considerava que o seu quintal era visagento, mas não obtivemos sucesso. Percebemos, sobretudo, que o silêncio diz muito nesses lugares, inclusive sobre respeito, sobre onde deve-se ou não ir, ainda mais a estrangeiros. Dona Joana disse que não acredita em visagens com grande simplicidade, que acredita na maldade do homem, principalmente no olho-gordo, espécie de mau-olhado, ou inveja que traz má sorte. A calmaria de dona Joana nos fez acalmar também nossa curiosidade, sem pressa e com cuidado seguimos a caminhada.

\section{4. Últimas considerações}

Como já foi dito anteriormente este estudo encontra-se em fase preliminar, encontram-se aqui mais questões que norteiam a pesquisa no momento em que se encontra, do que propriamente conclusões. O universo das plantas medicinais se apresentou como interessante porta de entrada às questões de caráter místico, envolvendo mulheres e o feminino na região. Se mostrou, também, como um campo de conhecimento vasto, que pode ser abordado de diversas perspectivas, desde o ponto de vista da relação entre humanos e não-humanos, neste caso, as plantas mágicas e de cura relacionadas ao conhecimento tradicional botânico de matriz complexa ameríndia-caboclo-quilombola.

No nosso ponto de vista este conhecimento está mergulhado em um imaginário complexo, onde constelam variadas imagens sensíveis sob eixos principais como o feminino, a fertilidade, o mistério, a vida e, principalmente, a intimidade. $\mathrm{O}$ espaço dos quintais se apresenta como um microcosmo de infindas simbologias. Nos curtos períodos em que convivemos com as duas senhoras nesses espaços, foram tantos os conhecimentos que nos repassaram, que seria impossível descrevê-los nessas páginas, mesmo que nossas conversas tivessem sido gravadas, inclusive porque não foram repassados somente através da oralidade, porque exploraram a linguagem dos sentidos e a dimensão do indizível. O que tem nos levado a profundos questionamentos sobre a forma de abordá-los, a necessidade ou não de transmiti- 
los fora do contexto etnográfico em que foram repassados e, ainda mais, a capacidade de traduzir tais experiências. Por isso as reflexões deste artigo giraram em torno de questões mais abrangentes acerca do perspectivismo, da cultura e do conhecimento de populações amazônicas no contexto marajoara.

\section{Referências}

BERQUE, Augustin. Paisagem-marca, paisagem-matriz: elementos da problemática para uma geografia cultural. In: CORRÊA, Roberto L. e ROSENDAHL, Zeni (orgs.). Paisagem, tempo e cultura. Rio de Janeiro: EdUERJ, 1998.

El pensamento paisajero. Madrid: Biblioteca Nueva, 2009.

CASTRO, Eduardo Viveiros de. A inconstância da alma selvagem e outros ensaios de antropologia. São Paulo: COSAC \& NAIFY, 2002.

CASTRO, Eduardo Viveiros. A floresta de cristal: notas sobre a ontologia dos espíritos amazônicos. Cadernos de campo, São Paulo, n. 14/15, p. 319-338, 2006.

GALVÃO, Eduardo. Vida religiosa do caboclo da Amazônia. Boletim do Museu Nacional, 15, 1953

GOLDMAN, Marcio. A relação afroindígena. In: Cadernos de campo, São Paulo, n. 23, 2014.

LÉVI-STRAUSS, Claude. Mito e Significado. Viseu: Edições 70, 1987.

MAUÉS, Raymundo Heraldo. Catolicismo, religiosidade e cultura popular entre pescadores e camponeses na Amazônia Oriental In: GODOI, Emilia Pietrafesa; MENEZES, Marilda Aparecida de;

MARIN, Rosa Acevedo (orgs.). Diversidade do campesinato: expressões e categorias: construções identitárias e sociabilidades, v.1. São Paulo: Editora UNESP; Brasília, DF: Núcleo de Estudos Agrários e Desenvolvimento Rural, 2009.

MAUÉS, Raymundo Heraldo. O perspectivismo indígena é somente indígena? Cosmologia, religião, medicina e populações rurais na Amazônia. Dossiê - Amazônia: Sociedade e Natureza. In: Mediações. Londrina, vol. 17, num. 01. 2012.

MAUSS, Marcel. Esboço de uma teoria geral da magia. In: Sociologia e Antropologia. São Paulo: COSACNAIF, 2003.

MOTTA-MAUÉS, Maria Angelica; VILLACORTA, Gisela Macambira. Matintapereras e pajés: gênero, corpo e cura na pajelança amazônica (Itapuá/PA). In: MAUÉS, Raymundo Heraldo;

VILLACORTA, Gisela Macambira (orgs.). Pajelanças e religiões africanas na Amazônia. Belém: EDUFPA, 2008.

SANTOS-GRANERO, Fernando. Vitalidades sensuais. Modos não corpóreos de sentir e conhecer na Amazônia indígena. Revista de antropologia. São Paulo: USP, 2006.

SILVEIRA, Flávio L. A. da. As paisagens fantásticas e o barroquismo das imagens. Estudo da memória coletiva dos contadores de causos da região missioneira do Rio Grande do Sul. Porto Alegre: Tese de Doutorado, UFRGS, 2004. 
WAWZYNIAK, João Valentim. Humanos e não-Humanos no universo transformacional dos ribeirinhos do rio Tapajós - Pará. Mediações, 1(17): 17-32, 2012.

WAWZYNIAK, João Valentin. "Engerar": uma categoria cosmológica sobre pessoa, saúde e corpo. In: ILHA. Florianópolis, v.5, n.2, dezembro 2003.

i Doutoranda do Programa de Pós-graduação Sociologia e Antropologia na Universidade Federal do Pará, mestre em Linguagens e Saberes na Amazônia e graduada e Ciências Sociais pela mesma universidade.

${ }^{2}$ Doutor em Antropologia Social. Professor do Programa em Linguagens e Saberes na Amazônia (PPLSA/UFPA). Pesquisador do CNPq.

${ }^{3}$ A Matinta ou Matintaperera é uma personagem mítica presente em grande parte da Amazônia que, comumente, consiste na metamorfose de uma mulher num grande pássaro. 